\title{
Management of Febrile Neutropenia - a German Prospective Hospital Cost Analysis in Lymphoproliferative Disorders, Non-Small Cell Lung Cancer, and Primary Breast Cancer
}

\author{
Angela Ihbe-Heffinger ${ }^{a, b} \quad$ Bernadette J. Paessens ${ }^{a} \quad$ Christoph von Schilling $^{c, d}$ \\ Margarita Shlaen ${ }^{\mathrm{e}}$ Nina Gottschalk ${ }^{\mathrm{b}}$ Karin Berger $^{\mathrm{f}}$ Rudolf Bernard ${ }^{\mathrm{a}}$ \\ Marion Kiechle ${ }^{b}$ Christian Peschel $^{c}$ Volker R. Jacobs ${ }^{b, g}$ \\ ${ }^{a}$ Krankenhausapotheke, ${ }^{b}$ Frauenklinik, ${ }^{c}$ III. Medizinische Klinik, Klinikum rechts der Isar (MRI) der Technischen Universität München, \\ ${ }^{\mathrm{d} M e d i z i n i s c h e ~ K l i n i k ~ I I I, ~ K l i n i k u m ~ F r e i s i n g, ~}{ }^{e}$ Health Economics und Outcomes Research, IMS HEALTH GmbH München, \\ ${ }^{f}$ Abteilung für Transfusionsmedizin und Hämostaseologie, Klinikum der Universität München, \\ gFrauenklinik, Universitätsklinikum Köln, Germany
}

\section{Keywords}

Costs and cost analysis - Neutropenia - Leukopenia . Health resources . Combined antineoplastic treatment protocols · Adverse effects

\section{Summary}

Background: Febrile neutropenia/leukopenia (FN/FL) is the most frequent dose-limiting toxicity of myelosuppressive chemotherapy, but German data on economic consequences are limited. Patients and Methods: A prospective, multicentre, longitudinal, observational study was carried out to evaluate the occurrence of $F N / F L$ and its impact on health resource utilization and costs in non-small cell lung cancer (NSCLC), lymphoproliferative disorder (LPD), and primary breast cancer (PBC) patients. Costs are presented from a hospital perspective. Results: A total of 325 consecutive patients (47\% LPD, 37\% NSCLC, $16 \%$ PBC; $46 \%$ women; $38 \%$ age $\geq 65$ years) with $68 \mathrm{FN} / \mathrm{FL}$ episodes were evaluated. FN/FL occurred in $22 \%$ of the LPD patients, $8 \%$ of the NSCLC patients, and $27 \%$ of the PBC patients. $55 \mathrm{FN} / \mathrm{FL}$ episodes were associated with at least 1 hospital stay (LPD $n=34$, NSCLC $\mathrm{n}=10, \mathrm{PBC} \mathrm{n}=11$ ). Mean (median) cost per FN/FL episode requiring hospital care amounted to $€ 3,950$ $(€ 2,355)$ and varied between $€ 4,808(€ 3,056)$ for LPD, $€ 3,627$ (€ 2,255) for NSCLC, and $€ 1,827$ (€ 1,969) for PBC patients. $12 \mathrm{FN} / \mathrm{FL}$ episodes (LPD $\mathrm{n}=9$, NSCLC $\mathrm{n}=3$ ) accounted for $60 \%$ of the total expenses. Main cost drivers were hospitalization and drugs (60 and 19\% of the total costs). Conclusions: FN/FL treatment has economic relevance for hospitals. Costs vary between tumour types, being significantly higher for LPD compared to PBC patients. The impact of clinical characteristics on asymmetrically distributed costs needs further evaluation.

\section{Schlüsselwörter}

Kosten und Kostenanalyse - Neutropenie - Leukopenie . Gesundheitsressourcen - Kombinierte antitumoröse Behandlungsprotokolle $\cdot$ Nebenwirkungen

\section{Zusammenfassung}

Hintergrund: Febrile Neutropenie/Leukopenie (FN/FL) ist die häufigste dosislimitierende Toxizität myelosuppressiver Chemotherapien. Bezüglich ökonomischer Konsequenzen fehlen deutsche Daten jedoch weitgehend. Patienten und Methoden: Eine prospektive, multizentrische, longitudinale Beobachtungsstudie zur Erfassung der Häufigkeit der FN/FL, des Behandlungsmanagement-assoziierten Ressourcenverbrauchs und der Kosten bei Patienten mit nicht-kleinzelligem Bronchialkarzinom (NSCLC), lymphoproliferativen Erkrankungen (LPD) oder primärem Brustkrebs (PBC) wurde durchgeführt. Die Kostendarstellung erfolgt aus der Krankenhausperspektive. Ergebnisse: Insgesamt waren 325 konsekutive Patienten (47\% LPD, 37\% NSCLC, 16\% PBC; 46\% weiblich; $38 \%$ Alter $\geq 65$ Jahre) mit 68 FN/FL-Episoden auswertbar. FN/FL trat in $22 \%$ der LPD-, $8 \%$ der NSCLC- und $27 \%$ der PBC-Patienten auf. Insgesamt waren 55 FN/FL-Episoden mit mindestens einer Behandlung am Krankenhaus assoziiert (LPD $n=34$, NSCLC $n=10$, PBC $n=11$ ). Die durchschnittlichen (medianen) Kosten pro FN/FL-Episode mit Krankenhausaufenthalt betrugen $€ 3.950$ ( $€ 2.355$ ) und variierten zwischen $€ 4.808$ ( $€$ 3.056) für LPD, $€ 3.627$ ( $€ 2.255$ ) für NSCLC und $€ 1.827$ (€ 1.969) für PBC Patienten. 12 FN/FL-Episoden (LPD $\mathrm{n}=9$, NSCLC $\mathrm{n}=3$ ) bedingten $60 \%$ der Gesamtausgaben. Mit 60 und 19\% Anteil wurden die Krankenhaus-Basisleistungen und die medikamentöse Therapie als Kostentreiber identifiziert. Schlussfolgerungen: Die Behandlung der FN/FL ist für Krankenhäuser ökonomisch relevant. Die Durchschnittskosten variieren in Abhängigkeit von der Tumorart mit signifikant erhöhten Kosten für LPD- im Vergleich zu PCB-Patienten. Der Einfluss klinischer Faktoren auf die asymmetrisch verteilten Kosten sollte weiter erforscht werden.

\section{KARGER \\ Fax +497614520714 \\ Information@Karger.de}

www.karger.com (c) 2011 S. Karger GmbH, Freiburg

0378-584X/11/0345-0241\$38.00/0

Accessible online at:

www.karger.com/onk
Dr. rer. nat. Angela Ihbe-Heffinger

Klinikum rechts der Isar der Technischen Universität München (TUM)

Krankenhausapotheke und Frauenklinik

Ismaninger Straße 22, 81675 München, Germany

Tel. +49 89 41406-169, Fax -365

Angela.Jhbe-Heffinger@lrz.tum.de 


\section{Introduction}

Febrile neutropenia (FN) is considered a potential life-threatening emergency in patients receiving myelosuppressive chemotherapy (CTX) for cancer. As patients with a reduced white blood cell count (WBC) are especially vulnerable to all kinds of infections [1] and fever is often the only warning sign, immediate medical attention is necessary to prevent infection as early as possible [2]. Therefore, FN usually leads to hospitalization and treatment with broad spectrum antibiotics [3]. The result is often a dose limitation up to a delay of the next CTX cycle $[4,5]$.

Aside from the clinical consequences, routine management of neutropenia and FN has a considerable economic impact, particularly in the inpatient setting [6]. Currently, the existing health economic literature mainly originates from the United States. Mean costs for neutropenia-related care there recently were $\$ 12,397$ per patient [7]. With $\$ 19,110$, mean costs per episode associated with the more severe FN can be markedly higher [8]. Moreover, cancer type and level of care seem to have a substantial impact on FN management costs. In a pilot study with community oncology cancer patients, total direct inpatient costs were on average $\$ 17,869$ for lymphoma compared to $\$ 10,354$ for breast cancer patients [9]. Direct costs for outpatients were remarkably lower (lymphoma: $\$ 5,704$; breast cancer: \$1,094).

American data tend to report substantially higher costs than those for Europe. A Spain retrospective study estimates $€ 3,841$ mean direct cost per episode attributable to FN [10]. Although pressure on health care budgets is constantly rising, especially for Germany microeconomic data on supportive care interventions are very limited. As supportive care issues are especially large in patients with non-small cell lung cancer (NSCLC), lymphoproliferative diseases (LPD), and primary breast cancer (PBC), the occurrence of FN and its impact on health resource utilization and costs were therefore prospectively investigated in this group of patients in a noninterventional setting.

\section{Patients and Methods}

Study Design

This was a subgroup analysis of a prospective, longitudinal, multicentre, observational study [11] with consecutive patient recruiting between January 2005 and December 2006 in 4 Bavarian hospitals in Germany ( $\mathrm{n}=2$ universities; $\mathrm{n}=2$ standard care). Centres were selected to be experienced in the administration of CTX and represent all levels of current hospital cancer care. Patient follow-up lasted until June 2007. Analysis of resource consumption and costs was performed from the hospital provider's perspective. The study was approved by the hospitals' local ethics committees, and written informed consent was obtained from all patients.

\section{Patients}

The study population consisted of patients fulfilling the following inclusion criteria: 1st or 2nd line (immuno)-CTX for NSCLC, LPD, or PBC. PBC patients had to be undergoing an anthracycline- or taxane-based (neo) adjuvant schedule. To avoid inclusion of patients whose CTX was only initiated at study site, patients had to be scheduled for at least 2 CTX visits. Patients receiving myeloablative CTX with stem cell support were excluded, as were those who were unable to participate in patient interviews for linguistic or cognitive reasons. Recurrent enrolment was possible.

\section{Data Collection}

Basic demographics and clinical history at first enrolment as well as anticancer treatment characteristics and toxicity-associated resource usage were collected by pre-planned chart abstraction. Occurrence and severity of CTX-induced toxicity were recorded at each CTX visit using a structured interview or by telephone after the final CTX visit according to the NCI CTCAE v3.0 and the causality criteria of the World Health Organisation Uppsala Monitoring Centre (WHO-UMC) [12].

Laboratory tests including WBC were recommended on a weekly basis. In the case of fever, outpatients were advised to contact their physician for assessment of haematological counts. If nadir monitoring was provided by external institutions, a written demand requesting to disclose nadir blood counts was issued via the patient. FN was incorporated into analysis as a composed variable. FN was defined as fever $\geq 38^{\circ} \mathrm{C}$ and an absolute neutrophil count $(\mathrm{ANC})<1 \times 10^{9} / 1$. If nadir ANC was unavailable, febrile leukopenia (FL) was assessed (leukocytes $<2 \times 10^{9} / 1$ and fever $\geq 38^{\circ} \mathrm{C}$ ). Granulocyte colony-stimulating factor (G-CSF) use was considered as prophylaxis if started between $24 \mathrm{~h}$ and $120 \mathrm{~h}$ after CTX [13].

To evaluate costs from the hospital provider's perspective, the quantified resource use associated with an FN/FL episode was multiplied by the respective unit cost for each resource. Cost data sources used for calculation were as follows: i) Drugs and blood products: local actual costs for supply (Hospital Pharmacy and Transfusion Unit of the Klinikum rechts der Isar (MRI) in 2007; ii) Diagnostics: DKG-NT (Deutsche Krankenhausgesellschaft-Normaltarif; Standard Rate of the German Hospital Federation 2005, column 7: full cost); iii) Hospitalization: local actual mean costs per day based on internal accounting data in 2007 (€ 259.50 for normal care, $€ 805.00$ for intensive care, and $€ 106.50$ for outpatient or day care).

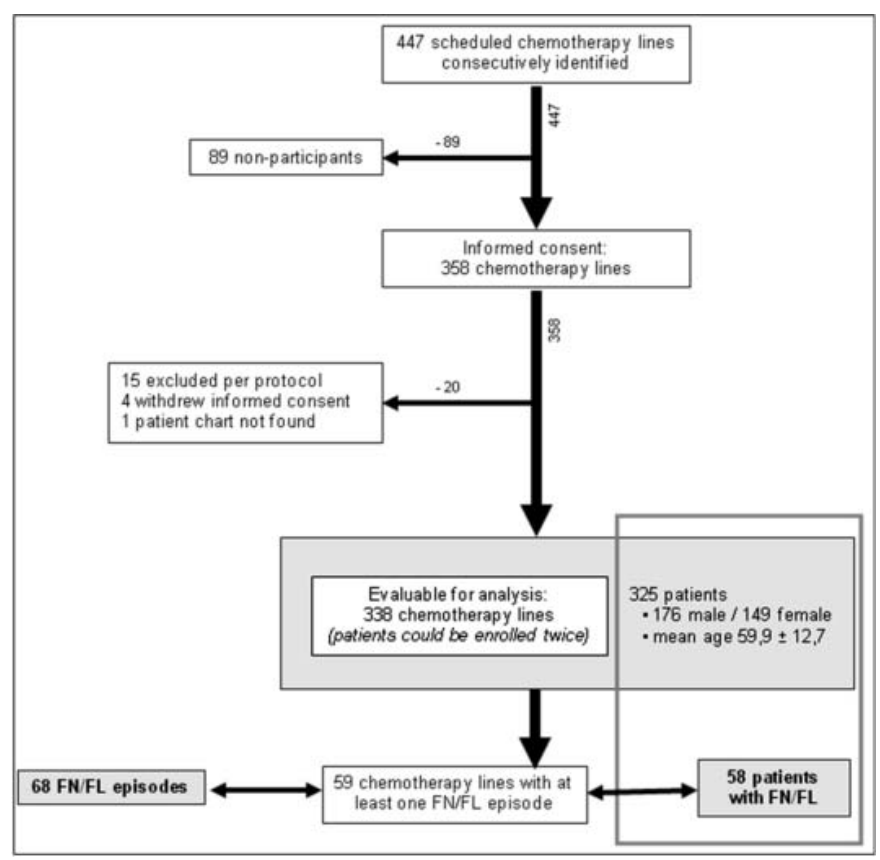

Fig. 1. Study flow chart. 
Table 1. Febrile neutropenia/febrile leukopenia (FN/FL) patient characteristics at 1st enrolment and anticancer treatment

\begin{tabular}{|c|c|c|c|c|}
\hline & Total $(\mathrm{n}=58)$ & $\operatorname{NSCLC}(n=9)$ & $\operatorname{LPD}(\mathrm{n}=35)$ & $\operatorname{PBC}(n=14)$ \\
\hline Females, n (\%) & $33(57)$ & $3(33)$ & $16(46)$ & $14(100)$ \\
\hline Age $^{\mathrm{a}}$, years & $58.1 \pm 14.5(54.3-61.9)$ & $60.7 \pm 8.1(54.5-66.9)$ & $59.0 \pm 16.5(53.3-64.6)$ & $54.1 \pm 12.4(47.0-61.3)$ \\
\hline Age $\geq 65$ years, $n(\%)$ & $22(38)$ & $3(33)$ & $16(46)$ & $3(21)$ \\
\hline Height $^{\mathrm{a}}, \mathrm{cm}$ & $168.9 \pm 8.2(166.8-171.1)$ & $170.7 \pm 8.0(164.5-176.8)$ & $170.0 \pm 8.1\{167.2-172.8)$ & $165.1 \pm 7.8(160.6-169.6)$ \\
\hline Weight $^{\mathrm{a}}, \mathrm{kg}$ & $72.6 \pm 12.3(69.4-75.9)$ & $70.3 \pm 8.0(64.2-76.5)$ & $73.6 \pm 12.2(69.3-77.8)$ & $71.8 \pm 15.2(63.0-80.6)$ \\
\hline $\mathrm{ECOG} \geq 2, \mathrm{n}(\%)$ & $6(10)$ & $2(22)$ & $4(11)$ & $0(0)$ \\
\hline $2^{\text {nd }}$ line $\mathrm{CTX}^{\mathrm{c}, \mathrm{d}}, \mathrm{n}(\%)$ & $9(15)$ & $2(20)$ & $6(17)$ & $1(7)$ \\
\hline CTX regime $^{\mathrm{c}}, \mathrm{n}(\%)$ & & $9(80)^{f}$ & $19(54)^{\mathrm{g}}$ & $5(36)^{\mathrm{h}}$ \\
\hline Overall CTX cycles $^{\mathrm{a}, \mathrm{c}}$ & & $4.9 \pm 1.9(2.7-5.5)$ & $4.3 \pm 2.4(3.5-5.1)$ & $5.2 \pm 1.4(4.4-6.0)$ \\
\hline G-CSF prophylaxis ${ }^{\mathrm{c}, \mathrm{e}}$ & $18(31)$ & 0 & $15(43)$ & $3(21)$ \\
\hline
\end{tabular}

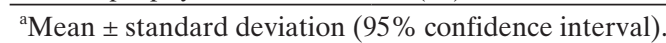

'LPD: CLL - Binet stage A was transformed to Ray stage 0, none of the CLL patients had tumour stage > Binet A; PBC: t-stage

${ }^{\mathrm{c}}$ Percentage of $\mathrm{n}=59$ CTX lines

${ }^{\mathrm{d}} \mathrm{n}=4$ missing.

${ }^{\mathrm{e}}$ Start of G-CSF treatment $\geq 24 \mathrm{~h}$ and $\leq 120 \mathrm{~h}$ after CTX [13].

${ }^{\text {fPlatinum-based. }}$

${ }^{\mathrm{g}} \mathrm{CHOP}$-like.

${ }^{\mathrm{h}}$ Anthracyclin + taxane-based.

NSCLC $=$ Non-small cell lung cancer; LPD = lymphoproliferative diseases; $\mathrm{PBC}=$ primary breast cancer; CTX = chemotherapy;

$\mathrm{CLL}=$ chronic lymphocytic leukaemia; G-CSF = granulocyte-colony stimulating factor.

Table 2. Level of care during febrile neutropenia/febrile leukopenia (FN/FL) episodes (all FN/FL episodes: $\mathrm{n}=68$, FN: $\mathrm{n}=28$; FL: $\mathrm{n}=40$ )

\begin{tabular}{llll}
\hline & $\begin{array}{l}\text { FN/FL episodes with } \\
\text { hospital treatment, } \mathrm{n}(\%)\end{array}$ & $\begin{array}{l}\text { Length of hospital stay }^{\mathrm{b}}, \\
\text { days, mean } \pm \mathrm{SD}(95 \% \text { CI })\end{array}$ & $\begin{array}{l}\text { Median } \\
\text { (range) }\end{array}$ \\
\hline Total & $55(81)$ & & \\
Inpatient care $^{\mathrm{a}}$ & $49(72)$ & $8.8 \pm 5.9(7.1-10.5)$ & $7(1-30)$ \\
$\quad$ Intensive care & $5(7)$ & $11.0 \pm 11.5(-3.3-25.3)$ & $9(2-30)$ \\
$\quad$ Normal care & $46(65)$ & $8.2 \pm 5.1(6.7-9.7)$ & $7(1-24)$ \\
Outpatient/day care & $15(20)$ & $1.5 \pm 1(1-2)$ & $1(1-4)$ \\
\hline
\end{tabular}

${ }^{\text {a }}$ Re-hospitalisation or prolonged hospitalization due to FN/FL.

${ }^{\mathrm{b}}$ Per episode with stated level of care.
Statistical Analysis

Data were analyzed using the software Microsoft Excel 2002 and SAS version 8.0 (SAS Institute Inc., Cary, NC, USA). For descriptive purposes, frequency distribution of study parameters as well as mean, standard deviation (SD), median, and range were calculated. The $95 \%$ confidence interval (CI) was given when statistically appropriate.

\section{Results}

Study Population and Occurrence of FN/FL

A total of 325 patients including 338 CTX lines $(n=130$ NSCLC, $\mathrm{n}=156$ LPD, $\mathrm{n}=52$ PBC) were evaluable for analysis (fig. 1). Sixty-eight FN/FL episodes were observed in 59 CTX lines $(17.5 \%) ; 15.3 \%(n=9)$ received a 2 nd line CTX, $\mathrm{n}=6$ for LPD treatment. Stratified according to tumour type FN/FL episodes occurred in 10 NSCLC, 35 LDP, and 14 PBC CTX lines (7.7, 22.4, and 26.9\%, respectively). Seven cases had more than 1 FN/FL episode (1 NSCLC, 5 LPD, 1 PBC). Grade 4 neutropenia/leukopenia was documented in $67.6 \%$ of FN/FL episodes (NSCLC, 36.4\%, LPD 76.2\%, PBC 66.7\%). $\mathrm{FN} / \mathrm{FL}$ patients and anticancer treatment characteristics are summarized in table 1 . They differ markedly depending on tumour type. PBC patients were younger than patients with LPD or NSCLC. Nobody presented with ECOG $\geq 2$, and only 1 patient with stage III/IV disease. In contrast, all NSCLC patients with FN/FL had an advanced tumour stage. None of the NSCLC patients received G-CSF prophylaxis, while $43 \%$ of LPD and $21 \%$ of PBC cases did.

Resource Usage during FN/FL-Associated Hospital Treatment Data on the level of hospital care during FN/FL episodes are summarized in table 2. In total, $68 \mathrm{FN} / \mathrm{FL}$ episodes were observed; 13 episodes (29\%) were resolved without, 55 (81\%) with additional hospital care. Inpatient management with a 7 -day median length of stay was more frequent than outpatient or day care (72 vs. $20 \%$ ). Intensive care was necessary in 5 episodes $(7 \%)$. Three episodes could not be included in the detailed analysis of resource usage because of missing data (fig. 2). A total of $88 \%$ of episodes were treated with drug therapy. Frequently used drugs were antibiotics $(83 \%)$, antimycotics (29\%), G-CSF (27\%), and virustatics (19\%). Blood products including red blood cells, platelets, fresh 


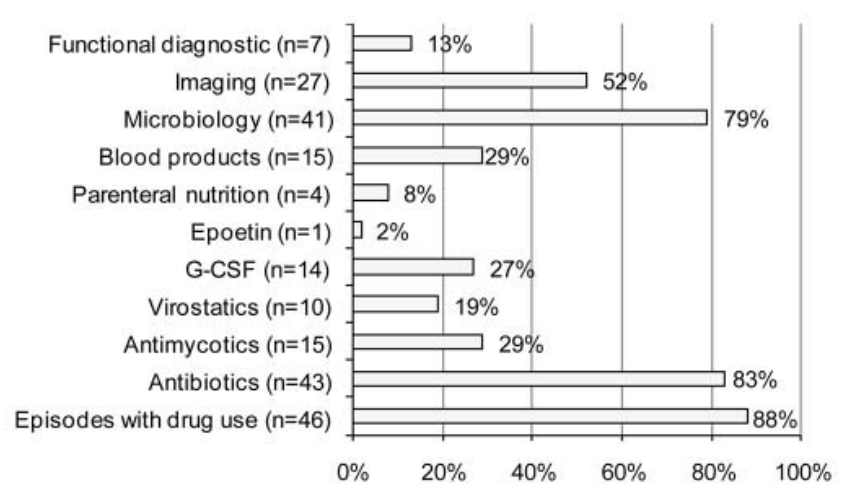

Fig. 2. Febrile neutropenia/febrile leukopenia (FN/FL) episodes with resource use during hospital treatment $(\mathrm{n}=52 ; \mathrm{n}=3$ episodes with missing data regarding detailed resource use).

frozen plasma, albumin, and antithrombin III were reported in $29 \%$ of episodes. The most relevant diagnostic procedure was microbiology testing $(79 \%)$.

\section{Costs}

Costs associated with the management of an FN/FL episode are presented in table 3, stratified according to cancer type. Mean (median) cost per episode totalled $€ 3,950$ (€ 2,355); 95\% CI: $€ 2,568-5,332$. Cost drivers are basic performance of the department (hospitalization) and drugs. They account for 60 and $19 \%$, respectively of the total mean cost. For patients with LPD, total mean costs are significantly higher than for PCB patients (€ 4,808 vs. $€ 1,827$ ). This is mainly due to significantly higher costs for drugs, blood products, and microbiology testing. Mean total costs of $€ 3,627$ per FN/FL episode occurred for NSCLC patients. Frequency distribution of FN/ FL-associated management costs is asymmetric; $23 \%$ of episodes ( $\mathrm{n}=9 \mathrm{LPD} ; \mathrm{n}=3$ NSCLC) generated $60 \%$ of the total economic burden in the observed cohort (fig. 3). There were no PCB patients in this high-cost subgroup.

\section{Discussion}

This study confirms that FN/FL is an expensive complication of myelosuppressive CTX, also in Germany. Compared to the management of CTX-induced nausea and vomiting, mean costs per cycle or episode with toxicity are considerably higher (€ 61 vs. $€ 3,950$ ) from a hospital perspective [14].

\section{Cost of FN Management}

Full published data on the burden of disease in Germany after the introduction of German Diagnosis-Related Groups (GDRGs) in 2004 are not available. From a 1998 German health insurance perspective, $€ 2,396$ mean FL-associated costs occurred in 13 small cell lung cancer patients (SCLC), as were $€ 3,192$ in 26 non-Hodgkin's lymphoma (NHL) patients per episode with neutropenia, fever, and/or infections $[15,16]$.

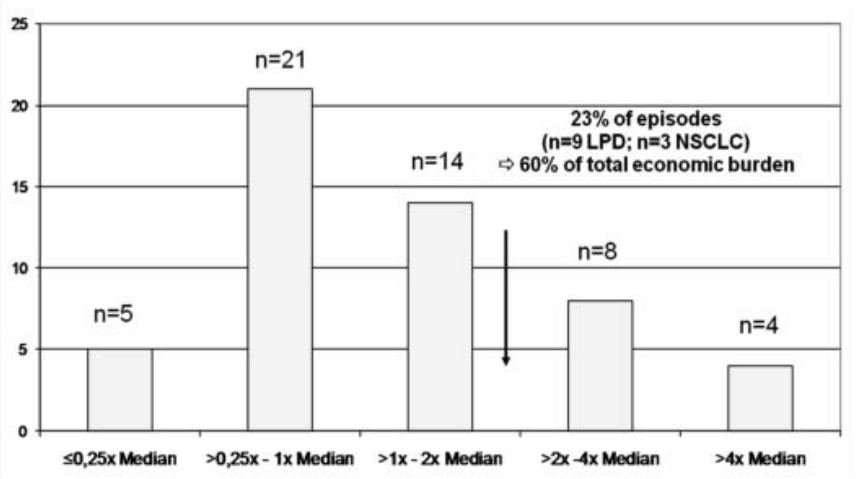

Fig. 3. Frequency distribution of febrile neutropenia/febrile leukopenia (FN/FL)-associated costs per episode $(\mathrm{n}=52 ; \mathrm{n}=3$ episodes with missing data regarding detailed resource use); median $€ 2,355$.

Although European health care systems differ, direct cost estimates of FN management are similar to our results. From a Dutch health care payer's perspective, $€ 3,290$ per FN episode were established for SCLC patients [15, 17]. Similar to our results, a recently published Spanish retrospective study reports FN-related costs depending on tumour type [10]. Costs were highest if NHL was the underlying cancer ( $€$ 4,514). For patients with lung and breast cancer, FN-related costs were considerably cheaper ( $€ 3,310$ and $€ 3,518$; significantly for lung cancer patients).

In contrast to the mixed breast cancer population ( $40 \%$ stage IV; $39 \%>60$ years) investigated by Mayordomo et al. [10], we studied a cohort of PBC patients $(7 \% \geq$ stage III; $21 \%>65$ years). Surprisingly, costs per FN episode were reduced by half $(€ 1,827)$ and differed significantly from our LPD cohort ( $€ 4,808)$. Similar cost estimates were found in a PCB cohort with 1-3 positive axillary lymph nodes, including 12 toxicity-associated re-hospitalisations with mean direct costs of $€ 2,209$ [18]. Therefore, besides tumour type, other patient- or treatment-related factors seem to influence FNassociated costs.

With approximately $23 \%$ of FN episodes producing $60 \%$ of the total economic burden, cost distribution is asymmetric. Therefore, mean $\mathrm{FN}$-associated costs $(€ 3,950)$ markedly differ from median costs ( $€ 2,355)$. Typically, mean costs serve as cost estimates in health economic models. Overestimation of actual cost-effectiveness could be the consequence. This may be crucial when results of health economic models influence reimbursement decisions and supportive care guidelines.

Since toxicity management was covered mainly by the participating study centres, downstream resource consumption (e.g. consultation of a general practitioner) was estimated to be low. A considerable proportion of cancer patients in Germany receives an obligatory sick leave for the entire CTX period or is already retired. Earlier data therefore had shown a small number of workdays lost attributable to CTX-induced toxicity [14]. That is why FN-associated indirect costs were not considered in this study. 
Table 3. Provider's perspective: febrile neutropenia/febrile leukopenia (FN/FL)-associated costs per episode

\begin{tabular}{lllll}
\hline Cost factors & \multicolumn{2}{l}{ Costs, $€$ mean (median) $(95 \%$ confidence interval) } & & \\
\cline { 2 - 5 } & Total $(\mathrm{n}=52)^{\mathrm{a}}$ & NSCLC $(\mathrm{n}=10)$ & LPD $(\mathrm{n}=31)$ & PBC $(\mathrm{n}=11)$ \\
\hline Basic hospital costs $^{\mathrm{b}}$ & $2,386(1,870)(1,824-2,948)$ & $2,568(1,817)(693-4,442)$ & $2,634(1,923)(1,870-3,399)$ & $1,522(1,557)(1,033-2,011)$ \\
Drugs $^{\mathrm{c}}$ & $744(197)(281-1,208)$ & $407(197)(56-759)$ & $1,059(422)(292-1,825)$ & $163(141)(39-288)$ \\
Blood products $^{\mathrm{d}}$ & $260(0)(-100-620)$ & $252(0)(-218-721)$ & $355(0)(-246-956)$ & $0(0)$ \\
Parenteral nutrition & $24(0)(-10-58)$ & $10(0)(-6-25)$ & $38(0)(-20-96)$ & $0(0)$ \\
Imaging & $81(28)(18-143)$ & $35(39)(-9-79)$ & $118(39)(14-223)$ & $16(39)(3-28)$ \\
Functional diagnostics & $2(0)(-1-5)$ & $0(0)$ & $3(0)(-2-8)$ & $0(0)$ \\
Microbiology & $263(50)(102-423)$ & $274(36)(-127-674)$ & $342(178)(99-586)$ & $28(7)(-6-61)$ \\
Blood tests & $97(90)(81-113)$ & $82(57)(31-132)$ & $107(94)(85-129)$ & $84(74)(68-99)$ \\
Other & $93(0)(-77-262)$ & 0 & $151(0)(-138-439)$ & $15(13)(5-24)$ \\
Total & $3,950(2,355)(2,569-5,331)$ & $3,627(2,255)(680-6,574)$ & $4,808(3,056)(2,666-6,949)$ & $1,827(1,969)(1,293-2,361)$
\end{tabular}

${ }^{\mathrm{a}} \mathrm{n}=3$ missing for detailed resource usage.

${ }^{\mathrm{b}}$ Cost for clinic performance: hotel, staff, medical and non-medical consumables, overheads; all other expenditures were added.

${ }^{\circ}$ Epoetin, G-CSF, virostatics, antimycotics, antibiotics, other drugs.

${ }^{\mathrm{d}}$ Red blood cells, platelets, FFP, antithrombin III, albumin.

${ }^{\mathrm{e}}$ Dialysis, consults.

NSCLC $=$ Non-small cell lung cancer; LPD = lymphoproliferative diseases; $\mathrm{PBC}=$ primary breast cancer; $\mathrm{G}-\mathrm{CSF}=$ granulocyte-colony stimulating factor; FFP = fresh frozen plasma.

Referring to sensitivity analyses performed for the underlying study [19], cost results were most sensitive regarding costs of hospital basic services (maximum variation: $\pm 14 \%$ ).

\section{Clinical Implications and Further Research}

Although studies from the United States consistently report higher FN management costs, frequency distribution of FNassociated length of stay - which directly corresponds to FNassociated hospitalization costs - was shown to be similarly asymmetric [8]. As a result, predictors for high FN management costs should contribute to improve cost-effectiveness of current supportive care strategies, irrespective of differences in health care systems. Patient and treatment characteristics such as age, leukaemia, hypovolaemia, co-morbidities, and infectious complications are associated with increased mortality, length of stay, and cost due to FN $[8,20,21]$. In an additional generalized linear regression model of this data, grade of neutropenia/leukopenia and CTX line were associated with higher FN management costs. Further confirmatory research with higher sample sizes is warranted. In conclusion, this study confirms that FN/FL has considerable economic consequences for German hospitals. Costs vary between tumour types, being significantly higher for LPD compared to PBC patients. Main cost drivers are hospitalization and drugs. To improve cost-effectiveness of current supportive care strategies, the impact of clinical characteristics on asymmetrically distributed FN management costs needs further evaluation.

\section{Acknowledgements}

This subanalysis was supported by Amgen GmbH, München, Germany, the underlying investigator-sponsored study [19] was supported by Lilly Deutschland GmbH, Bad Homburg, Germany. We thank Dirk Eheberg for his editorial assistance.

\section{Disclosure Statement}

Angela Ihbe-Heffinger: Research grant (Lilly, Amgen, Germany); honoraria (Amgen, Germany). Volker R. Jacobs: Research grant (Amgen, Germany). All other authors declared no conflict of interests.

\section{References}

1 Bodey GP, Buckley M, Sathe YS, Freireich EJ Quantitative relationships between circulating leukocytes and infection in patients with acute leukemia. Ann Intern Med 1966;64:328-340.

2 Pizzo PA: Management of fever in patients with cancer and treatment-induced neutropenia. N Engl J Med 1993:328:1323-1332.
3 Link H, Bohme A, Cornely OA, Hoffken K, Kellner O, Kern WV, Mahlberg R, Maschmeyer G, Nowrousian MR, Ostermann H, Ruhnke M, Sezer O, Schiel X, Wilhelm M, Auner HW: Antimicrobial therapy of unexplained fever in neutropenic patients - guidelines of the Infectious Diseases Working Party (AGIHO) of the German Society of Hematology and Oncology (DGHO), Study Group Interventional Therapy of Unexplained Fever, Arbeitsgemeinschaft Supportivmassnahmen in der Onkologie (ASO) of the Deutsche Krebsgesellschaft (DKG-German Cancer Society). Ann Hematol 2003;82(suppl 2):S105-117.
4 Lyman GH, Dale DC, Crawford J: Incidence and predictors of low dose-intensity in adjuvant breast cancer chemotherapy: a nationwide study of community practices. J Clin Oncol 2003;21:45244531.

5 Lyman GH, Dale DC, Friedberg J, Crawford J, Fisher RI: Incidence and predictors of low chemotherapy dose-intensity in aggressive non-Hodgkin's lymphoma: a nationwide study. J Clin Oncol 2004;22:4302-4311.

6 Liou S: Economic burden of haematological adverse effects in cancer patients: a systematic review. Clin Drug Investig 2007;27:381-396. 
7 Weycker D, Malin J, Edelsberg J, Glass A, Gokhale M, Oster G: Cost of neutropenic complications of chemotherapy. Ann Oncol 2008;19:454 460.

8 Kuderer NM, Dale DC, Crawford J, Cosler LE, Lyman GH: Mortality, morbidity, and cost associated with febrile neutropenia in adult cancer patients. Cancer 2006;106:2258-2266.

9 Bennett CL, Calhoun EA: Evaluating the total costs of chemotherapy-induced febrile neutropenia: results from a pilot study with community oncology cancer patients. Oncologist 2007;12:478483.

10 Mayordomo JI, Lopez A, Vinolas N, Castellanos J, Pernas S, Domingo Alonso J, Frau A, Layola M, Antonio Gasquet J, Sanchez J: Retrospective cost analysis of management of febrile neutropenia in cancer patients in Spain. Curr Med Res Opin 2009;25:2533-2542.

11 Paessens BJ, von Schilling C, Ehlken B, Shlaen M, Berger K, Bernard R, Peschel C, Ihbe-Heffinger A Resource use and costs associated with routine management of chemotherapy associated toxicity in German hospitals. Ann Oncol 2008;19(suppl 8):viii272 (886O).

12 The Uppsala Monitoring Centre: The use of the WHO-UMC system for standardised case causality assessment; www.who-umc.org/graphics/4409.pdf.
13 Smith TJ, Khatcheressian J, Lyman GH, Ozer H, Armitage JO, Balducci L, Bennett CL, Cantor SB, Crawford J, Cross SJ, Demetri G, Desch CE, Pizzo PA, Schiffer CA, Schwartzberg L, Somerfield MR, Somlo G, Wade JC, Wade JL, Winn RJ, Wozniak AJ, Wolff AC: 2006 update of recommendations for the use of white blood cell growth factors: an evidence-based clinical practice guideline. J Clin Oncol 2006;24:3187-3205.

14 Ihbe-Heffinger A, Ehlken B, Bernard R, Berger K, Peschel C, Eichler HG, Deuson R, Thodtmann J, Lordick F: The impact of delayed chemotherapyinduced nausea and vomiting on patients, health resource utilization and costs in German cancer centers. Ann Oncol 2004;15:526-536.

15 Tjan-Heijnen VC, Caleo S, Postmus PE, Ardizzoni A, Burghouts JT, Buccholz E, Biesma B, Gorlia T, Crott R, Giaccone G, Debruyne C, Manegold C: Economic evaluation of antibiotic prophylaxis in small-cell lung cancer patients receiving chemotherapy: an EORTC double-blind placebo-controlled phase III study (08923). Ann Oncol 2003; 14:248-257.

16 Herold M, Hieke K: Costs of toxicity during chemotherapy with $\mathrm{CHOP}, \mathrm{COP} / \mathrm{CVP}$, and fludarabine. Eur J Health Econ 2002;3:166-172.
17 Timmer-Bonte JN, Adang EM, Termeer E, Severens JL, Tjan-Heijnen VC: Modeling the cost effectiveness of secondary febrile neutropenia prophylaxis during standard-dose chemotherapy. J Clin Oncol 2008;26:290-296.

18 Braun M, Jacobs VR, Wagenpfeil S, Sattler D, Harbeck N, Nitz U, Bernard R, Kuhn W, IhbeHeffinger A: Cost analysis comparing an anthracycline/docetaxel regimen to CMF in patients with early stage breast cancer. Onkologie 2009;32:473481.

19 Paessens BJ, von Schilling C, Berger K, Shlaen M, Müller-Thomas C, Bernard R, Peschel C, IhbeHeffinger A: Health resource consumption and costs attributable to chemotherapy-induced toxicity in German routine hospital care in lymphoproliferative disorder and nsclc patients. Ann Oncol 2011;DOI 10.1093/annonc/mdq759;Epub ahead of print

20 Klastersky J, Paesmans M, Rubenstein EB Boyer M, Elting L, Feld R, Gallagher J, Herrstedt J, Rapoport B, Rolston K, Talcott J: The multinational association for supportive care in cancer risk index: a multinational scoring system for identifying low-risk febrile neutropenic cancer patients. J Clin Oncol 2000;18:3038-3051.

21 Lalami Y, Paesmans M, Muanza F, Barette M, Plehiers B, Dubreucq L, Georgala A, Klastersky J: Can we predict the duration of chemotherapy-induced neutropenia in febrile neutropenic patients, focusing on regimen-specific risk factors? A retrospective analysis. Ann Oncol 2006;17:507-514. 